\title{
Virtual Reality Laboratories: A Way Forward for Schools?
}

\author{
Richard Lamb ${ }^{1 *}$, Jing Lin ${ }^{2}$, Jonah B Firestone ${ }^{3}$ \\ ${ }^{1}$ East Carolina University Neurocognition Science Laboratory, USA \\ ${ }^{2}$ Collaborative Innovation Center of Assessment for Basic Educational Quality, Beijing Normal University, CHINA \\ ${ }^{3}$ Washington State University, USA
}

Received 7 November 2019 - Accepted 10 April 2020

\begin{abstract}
In recent years, the applications of virtual reality (VR) in learning environments has received considerable attention. This attention occurs as a part of a wider trend seen since the early millennium. This trend is that of increasing attention being placed on modes of instruction that can supply greater realism and immersion in the science classroom. VR is used in this study as a digital learning environment support tool. VR is defined as the use of three-dimensional graphic systems in combination with various interfaces to provide the effect of immersion and interaction in computer generated environments. The purpose of this study was to investigate the barriers to content learning and immersion of a VR laboratory designed to replicated hands-on laboratory for a large university system. The primary means for data collection was the use of a combination multiple choice and open-ended survey response in conjunction with interviews. Twelve faculty and 285 students took part in a pilot program testing a VR based laboratory system as a part of an undergraduate life sciences class. Overall, the results suggest the VR system as it is currently implemented is not yet ready for large-scale implementation due to barriers related to immersion and interface in the classroom. This study also provides design recommendations that may assist in the further development for VR use in the classroom in future iterations.
\end{abstract}

Keywords: virtual reality, science laboratory, simulation

\section{INTRODUCTION}

In recent years, the applications of virtual reality (VR) in learning environments has received considerable attention (Lin \& Yu-Ju, 2015). This has occurred as a part of a wider trend that began at the end of the last millennium. Over the last 20 years, increasing attention by educators has been placed on modes of instruction that can supply greater realism and immersion (such as VR) in the science classroom (Waight, Liu, Gregorious, Smith, \& Park, 2014). The relative inexpensive and realistic nature of VR has fostered increased use of VR in the classroom. Estimates suggest that as many as $83 \%$ of teachers now have access to this technology in the classroom (Gray, 2010). This increase directly correlates not only with the shrinking cost of dedicated VR equipment, but with the ubiquitous use of VR capable 'smart phones' (Lawson, Salanitri, \& Waterfield, 2016). The adoption of VR has occurred not just at the K-12 level but at the university level as well. Surprisingly, with this growing level of adoption, there have been relatively few studies that explore the aspects of the VR experience which impede or enable learning in university science classrooms (Bower, Lee, \& Dalgarno, 2017).

University science classrooms benefit from VR due to the high level of immersive realism and environmental control (Potkonjak, Cardner, Callaghan, Mattila, Guetl, Pertrovic, \& Jovanovic, 2016). Investigations into the immersive learning aspects of VR illustrate the considerable potential for pedagogical applications in education, counseling, and other fields (Lamb, Etopio, Lamb, 2019; Riva, Banos, Botella, Mantovani, \& Gaggioli, 2016).

Several studies have probed technologies related to VR and its effect on science education regarding; (a) conceptual change (Clark \& Mayer, 2016), (b) laboratory work (Freeman, Eddy, McDonough, Smith, Okoroafor, Jordt, \& Wenderoth, 2014), (c) science inquiry-based 


\section{Contribution to the literature}

- Technological skill with VR is related to the student's history with online courses.

- Specific pedagogical approaches should be embedded in the software during the design process.

- Studies have found that, interactions in a VR environment can be a reasonable and valuable substitute for real life experiences.

learning (Crawford, Capps, van Driel, Lederman, Lederman, Luft, \& Wong, 2014), (d) scientific argumentation (Choi, Hand, \& Greenbowe, 2013), and (e) spatial ability (Lamb, 2016; Lamb, Annetta, Firestone, \& Etopio, 2018). The results of these studies are mostly limited to illustrating learners' attitudes related to VR (e.g., satisfaction or perceived usefulness), and only hint at possible improvement in student outcomes related to skill development and content. Even fewer studies have examined aspects of VR that may impede or enable learning.

Overall, educational research regarding VR is in its infancy (Dawley \& Dede, 2014). In order to extend this important line of research, this study provides evidence that VR technology may not only play a role in science learning but further clarifies barriers to implementation and future directions for the use of VR in K-12, university, and life-long education. This study also illuminates means and methods that teachers or instructors can use to improve VR use in classrooms as an integrated classroom technology. The study specifically examines authentic VR experiences that allow students to engage in science practices such as scientific investigations and data collection in immersive simulated environments. In addition, the students may interact with an avatar, and communicate face-to-face with peers. All of these activities are critical to the science education process (Decristan, et al., 2015).

Educational VR (EVR) has its conceptual roots in the early immersive Serious Educational Games (SEG) (Annetta, 2010). SEGs are games in which players engage in complex two-dimensional interactions designed specifically for learning. EVR takes this a step further making use of whole immersive environments in which specific, a priori, pedagogical approaches are developed during the initial design phase of the VR program. The intention of this form of VR is to teach not only skills but specific content making this approach different from much of the VR content currently commercially available. As this form of educational technology matures, EVR will provide greater opportunities for learning due to the immersive nature, interactivity, control and customizability of VR environments, and the realism of activities and tasks (Shute, Rahimi, \& Emhovich, 2017). This promotes the three critical aspects of VR immersion, fluidity, and authenticity (Lamb, 2019). EVR simulations allow students and instructors to examine phenomena at the microscale and macroscale levels with transition between the scales occurring simply by gesturing allowing for greater student control and exploration of the content (Lamb, 2016).

Continuing development of this technology will, within the next 5 to 10 years, provide new opportunities for teaching and learning in problem-based approaches that will be financially available to many, if not most, K12 schools and universities (Dunleavy \& Dede, 2014). While adoption may initially be slow, technology maturation and lower cost will facilitate movements to integrate EVR into the classroom. Integration of EVR will also likely occur due to the intensely immersive nature of this technology and related technologies such as augmented reality (Calogiuri et al., 2017).

\section{Immersion in Virtual Reality}

Immersion can take one of multiple forms: psychological, sensory, and/or physiological (Tan \& Nijholt, 2010). The mixture of these three forms of immersion in VR is what increases the learning opportunities in VR (Dalgarno \& Lee, 2010; Lamb, Annetta, Firestone, \& Etopio, 2018). Immersion in each of these three forms partially arises from the infusion of highly realistic digital content into virtual environments. The realism of these virtual environments makes them nearly indistinguishable from 'real' environments due to the use of $4 \mathrm{~K}$ or $8 \mathrm{~K}$ digital resolutions (approximately 4000 or 8000 horizontal pixels per screen as opposed to standard monitors that have approximately 2000 horizontal pixels) and spatial audio (Pinson, Barkowsky, \& Le Callet, 2013). These digital resolutions, spatial audio, and touch based sensory feedback, create a much sharper picture, more realistic sound, and a greater sense of kinesthetic feedback than has been previously possible. This greatly increases the levels of immersion. For example, if a VR world is designed for educational use in the sciences, the success of the psychological immersion is based on how involved the user becomes in the environment, how "realistic" the science content presented in the environment is, and how responsive the environment is to the users actions (Santos, Chen, Taketomi, Yamamoto, Miyazaki, \& Kato, 2014). In other words, the question becomes how "believable" is the environment and how possible is it to suspend disbelief in terms of operating in the virtual environment?

Physiological immersion within the VR environment occurs when the user moves and receives feedback from the aforementioned visual, auditory, or haptic devices used to interact within the digital environment. The device must, in a responsive and in an interpretable way, 
change according to the user's movements and actions within the environment (Grassi, Zaretskaya, Bartels, Goerke, Milde, Bukowiecki, Kunz, Klika, Wiglenda, Mogk, \& Wanker, 2015). An example of an interpretable response in VR is as simple as when a person moves their head to the left the view field also moves left in a timely manner. The responsiveness of the VR system is particularly important in the context of VR science laboratories. Without proper immersion, integration of both practices (i.e. skills) and content learning are greatly reduced as a result of frustration (Merchant, Goetz, Cifuentes, Keeney-Kennicutt, \& Davis, 2014). More importantly, if the system is not responsive to the user, the user may experience vertigo or other dysphoric events (e.g. nausea) (Baldominos, Saez, \& del Pozo, 2015). When used appropriately, VR science laboratories that are built with a priori pedagogical approaches and include the visual, auditory, and haptics to cue users, promote greater learning outcomes (Schofield, 2014).

A second important feature of VR that separates it from other educational technologies is the real-time interactivity (fluidity) in a stereoscopic 3D environment (Potkonjak, Gardner, Callaghan, Mattila, Gueti, Petrovic, \& Jovanovic, 2016). Interactive responsiveness by the virtual environment results in more authentic and realworld like actions that aid in psychological immersion (Wood \& Reiners, 2015). Immersion occurs when the user is able to convert intention to action in the digital world. This allows users not only to visually interact with objects, but to physically manipulate objects (i.e. they touch and feel the objects using, auditory, haptic, and tactile inputs) (Klatzky, Giudice, Bennett, \& Loomis, 2014). The combination of psychological and physiological immersion produces sensory immersion (Hamari, Shernoff, Rowe, Coller, Asbell-Clarke, \& Edwards, 2016). While the primary draw to virtual reality is its immersive user interface, VR can also promote rich, interactive, problem-based learning, in fields such as engineering, medicine, and education (Savin-Baden, Poulton, Beaumont, \& Conradi, 2016). This promotion occurs because the VR environment triggers the human brain's capacity to process environmental inputs in the same way as in the real world (Lamb, 2019). In short, VR technology is well suited to convey difficult abstract concepts due to the visualization, interactivity, and immersivness of the environment to construct understanding by promoting new experiences and activating prior experiences (Psotka, 2013).

\section{VR and Constructivism}

In the process of developing VR based science laboratories in a constructivist approach, learners must be allowed to take an active role in their learning through environmental interaction (Vygotsky, 2016). Learners must also connect new information with prior, crystalized knowledge, in order to construct new knowledge (Vygotsky, 2016). The environments in which the learner finds themselves influence the learner through interactions with real or virtual structures, concepts, or events (Richards \& Taylor, 2015). Importantly, learners must be allowed to directly apply their knowledge in real-life or virtual contexts, engage in failure, and explore (Cordie, Lin, \& Whitton, 2017). Technologies such as VR allow all three of these to happen. In other words, science education should be experimental and experiential (Rosenblatt, Worthley, \& MacNab, 2013). In this framework, it is the educator's role to shape learners' experiences and understand how the surrounding environment promotes or impedes learning (Davis \& Singh, 2015).

Within the framework of construction of understanding in science, the focus of VR is on the learner's control of the learning processes. Therefore, EVR designs should attempt to tie knowledge as a discrete concept to real-life experiences and authentic tasks. A constructivist understanding, as it applies through VR, provides learners more freedom to select and coordinate their learning processes with other learners. As Kutlu (2012) suggested, constructivists emphasize the design of learning environments rather than instructional sequences. The learning environments should provide real-world, case-based environments for meaningful and authentic knowledge construction. In the case of science, experiences should provide means and opportunities to examine questions, claims, and evidence (Norton-Meier, Hand, Hockenberry, \& Wise, 2008).

Current research in educational technology suggests that constructivist principles fundamentally underlie learning in a VR environment (Lamb \& Annetta, 2012, 2013; Lui \& Slotta, 2014; Makani, Durier-Copp, Kiceniuk, \& Blandford, 2016; ). Constructivist learning in EVR is promoted through multiple characteristics: (a) constructivist learning involves the exploration, internalization, and discovery within the prebuilt, interactive, immersive representation of the real-world, through which prior knowledge is engaged and built upon, and (b) constructivist learning processes allow educators to examine pedagogical approaches and how VR features support learning in much the same way SEGs do (Annetta, 2010). Using educational virtual reality (EVR), students can learn in near real-life situations by engaging with tasks that, as closely as possible, approximate real-world tasks. This allows students to improve their skills and understandings through repeated practice not necessarily available in 'real-world' environments (e.g. repeating costly experiments over and over to get specific results). VR allows learners to interact with simulated environments in real time and engage with soft failure (Nelson \& Annetta, 2016). In addition, VR offers greater sensory cueing and multimodal feedback to enable the easy transfer of VR-learning into real-world understanding 
(Hancock, Mercado, Merlo, \& Van Erp, 2013). For example, learners can view 3D objects from multiple representations, viewpoints, and scales in addition to examining and exploring interactions and relationships. EVR used in more traditional classroom learning environments allows educators to provide experiences which otherwise would not be possible in science classrooms (e.g. seeing a virus infect a cell). Further, immersive environments create a strong sense of presence in the environment, which in turn motivates and thereby causes the learner to cognitively process the learning material more deeply (Katz \& Halpem, 2015). Presence in this context refers to the level of immersion in the environment and the degree to which the person "forgets" they are in a virtual environment. Neuroimaging studies reveal that when learners interact with VR environments the learners' cognitive systems process the VR immersive environment in the same way that real-world environments are processed (Lamb \& Etopio, 2019).

\section{Purpose and Areas of Examination}

The purpose of this study was to investigate the barriers and affordances of a VR laboratory designed to replicate hands-on laboratories in a large university system. Consideration of this purpose suggests the following research question. What characteristics of the examined virtual reality laboratory impact student engagement and learning? The authors of the study contend that the use of the VR based laboratory will make use of the listed affordances and influence student engagement and learning:

1) provide students access to a laboratory experience which may otherwise be unable to access due to resources or instructor constraints;

2) provide a real-world like laboratory environment, while attending to the content and laboratory experiences exclusively in the virtual world;

3) supplement student virtual experiences through connection to prior experiences with traditional wet-laboratory experience;

4) serve as an orientation or anticipatory learning set from which to scaffold "hands on" experience in future laboratories.

Substantiation of these affordances provides a means by which VR may be used to augment student learning in science laboratories. These insights may provide a greater understanding and identify potential uses of VR in future life science classes. In addition, this will provide evidence for modes of instruction that result in better student outcomes.
Table 1. Institution type and faculty participation

\begin{tabular}{lc}
\hline Institution Type & Number of Faculty \\
\hline Technology Campus & 15 \\
Community College & 47 \\
Comprehensive Four Year & 27 \\
Research Intensive & 20 \\
Non-System & 3 \\
\hline
\end{tabular}

\section{METHODS}

\section{Sample and Measurements}

The study was based upon student survey responses ( $n=128, N=285,45 \%$ response rate), randomly selected student interviews $(n=12, N=128)$, and randomly selected instructor interviews $(n=12, N=112)$. This design has the primary benefit of more closely aligning with 'normal' classroom conditions. This design also tended to minimize disruption of student learning and instructor planning.

One hundred and twelve faculty from a large university system received classroom test accounts and VR equipment for their laboratory students. Onehundred and twenty-eight students of the 285 students that took part in the EVR laboratories also chose to take part in an online survey related to their test account and VR based laboratory experiences. Classes consisted of undergraduates; $92 \%$ first-year students, $5 \%$ secondyear students, and 3\% third-year students. Students were $53 \%$ male, and $47 \%$ female. Students demographics consisted of $74 \%$ Caucasian, 18\% Asian, 3\% African American, and the remainder other ethnicities. Each institution made use of 16 modules designed for introductory life sciences course over a period of a19week semester.

The modules were selected by the instructors based upon alignment to current topics covered in their laboratory sections. VR apparatus consisted of Samsung Galaxy Gear VR Head Sets with Google Pixel phones running the VR laboratory software. Student participants were able to make use of the VR headsets both during the laboratory period and outside of the laboratory. Table 1 provides and overview of the type and number of the post-secondary institutions taking part in the study. Upon completion of the VR laboratory, instructors and students were asked to complete an assessment of five areas of concern and to engage in an open-ended interview with the researchers. The areas of concern were: Technical information is relevant to the discipline, Pre-laboratory lesson presentation, Learning outcomes, Student engagement, and Ease of content navigation. Instructors rated these areas on a 1 (Poor) through 7 (Excellent) scale.

The VR based laboratory is an immersive 3D problem based learning virtual simulation of several wet laboratories. The simulation makes use of realistic 3D animations to address laboratory-learning goals. The 

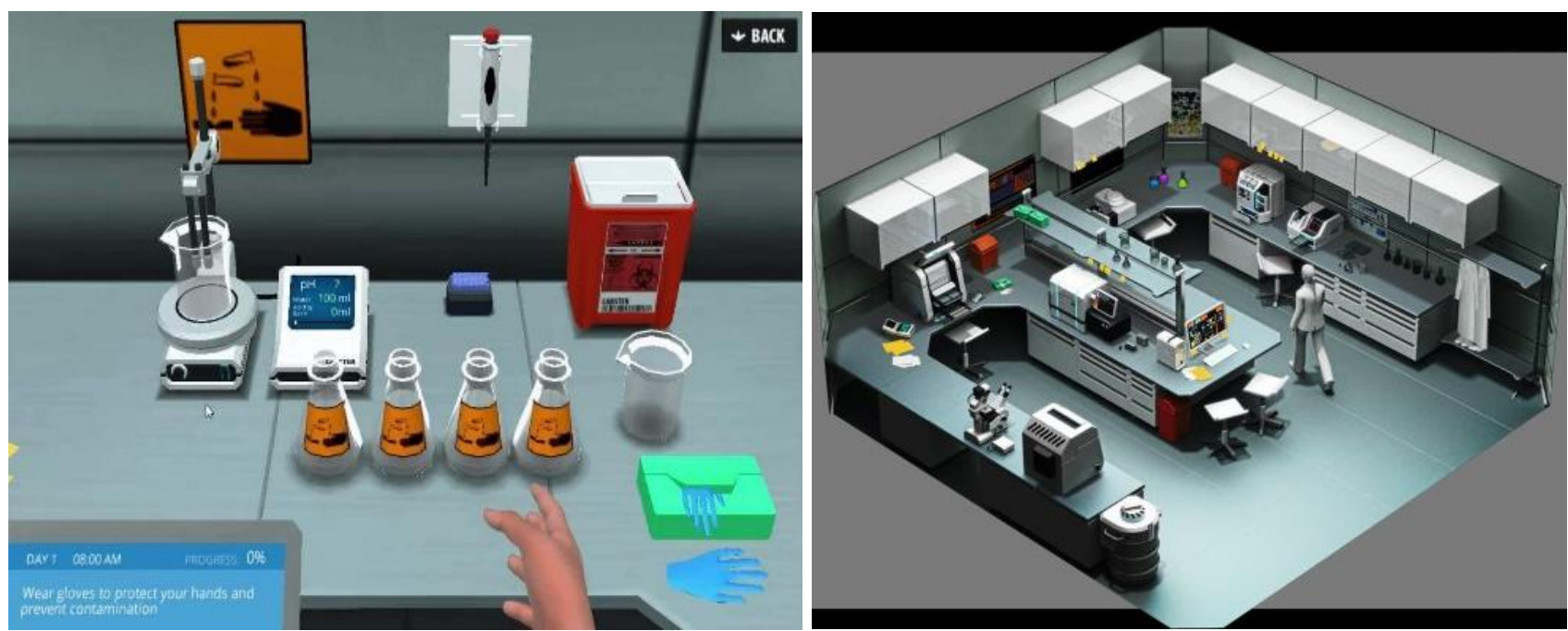

Figure 1. Left provides an overview of the laboratory bench; right provides overview of the full VR environment

animation allows students, when appropriate, to examine molecular scale representations as leaners engage in the performance of experiments. Figure 1 provides an overall view of the laboratory environment and bench workspace.

Responses to the questions were noted during openended unstructured interviews and triangulated with survey responses in which faculty members and students were asked to report on their experiences with the VR laboratory.

\section{Analysis}

Due to the exploratory nature of this study, the study authors engaged in a multimethods approach, data processing began with production of summary statistics from student survey responses and analysis of emergent themes from student and instructor interviews. Interview teams consisting of the author and a doctoral student recorded participant interviews using an audio recorder. Two of the authors listened to the recording, created transcripts, and identified statements which identify barriers or affordances associated with the EVR laboratory. Barrier and affordance identifications (e.g. trouble with the VR interface) by the first two authors were rated by a third team member for agreement. Interrater reliability was calculated using Fleiss's Kappa. Kappa was rated at .94 which is considered substantial agreement. During the development of the qualitative component of the study, VR outcomes were presented as relationships between characteristics of performance, which either impeded or promoted learning in relation to the use of the VR laboratory system. The interview participants in the study are a randomly selected subsample of students and instructors who were a part of the classes taking part in the study. Twenty-four participants (12-students and 12-instructors) were randomly selected from the top and bottom quartiles of the survey responses. Selection from these two quartiles occurred to maximize differences between groups in terms of survey results. This allowed researchers to between identify barriers and affordances which influenced activity across the sample. Using thematic inquiry, the authors were able generate possible themes for later development in future research studies. The authors also summarized data and identified potential relationships between the emergent themes. The current analysis is based on Jasper's (2011) theoretical propositions. The four theoretical propositions are: (1) individual actors in the system are interdependent, (2) linked actors occur due to shared resources, (3) the structure of the relations both constrains and facilitates action, and (4) patterns among actors define structure. Jasper's framework provides and important analytical framework as it allows greater understanding of the interactions between the VR technology, the students, and the instructors. There were six emergent themes arising from the analysis.

\section{RESULTS}

The most common theme emerging form the instructor interview was the relationship between the technological skill level of the student with respect to the VR and the student's history with online courses. In each case the italicized wording below each theme is the wording from the interview. These results provide a summary report of the interviews and responses from a survey and interview conducted with the instructors and the students. Overall, the results suggest that there are significant barriers to fully implementing VR in the classroom. Some barriers have to do with the nature of the technology and other barriers have to do with the nature of the students. Table 2 provides a descriptive, aggregate, summary of the student's assessment of the VR laboratory modules. Overall, there seems to be a negative assessment of the VR laboratory particularly in the areas of Ease of content navigation and Student engagement. These outcomes correspond to comments made during interviews. 
Table 2. Survey response frequencies for students $(n=128)$ taking part in the VR laboratory

\begin{tabular}{|c|c|c|c|c|c|c|c|}
\hline & 1 (poor) & 2 & 3 & 4 (Neutral) & 5 & 6 & 7 (excellent) \\
\hline Technical Information relevant to discipline & $15.8 \%$ & $13.2 \%$ & $2.6 \%$ & $15.8 \%$ & $13.2 \%$ & $10.5 \%$ & $15.8 \%$ \\
\hline Pre-lab lesson presentation & $21.1 \%$ & $13.2 \%$ & $5.3 \%$ & $13.2 \%$ & $21.1 \%$ & $5.3 \%$ & $5.3 \%$ \\
\hline Learning outcomes & $18.4 \%$ & $15.8 \%$ & $7.9 \%$ & $5.3 \%$ & $21.1 \%$ & $15.8 \%$ & $5.3 \%$ \\
\hline Student engagement & $26.3 \%$ & $13.2 \%$ & $15.8 \%$ & $7.9 \%$ & $15.8 \%$ & $5.3 \%$ & $5.3 \%$ \\
\hline Ease of content navigation & $36.8 \%$ & $15.8 \%$ & $13.2 \%$ & $13.2 \%$ & $0.0 \%$ & $7.9 \%$ & $7.9 \%$ \\
\hline
\end{tabular}

Theme 1: Technological savvy. Participants suggested that their savvy with technology played a major role in their acceptance of VR in the laboratory. Those participants with a lack of technological savvy found learning with the VR online software extremely difficult due to lack of interest in the content and practices associated with science arising from technological barriers. Much of this response results from frustration with the platform.

[Quote from Participant 1, Female, Second Year Student; Bottom Quartile]

"It was difficult to use the lab and the controls were hard to understand. I have not used VR or online labs very much. I need a lot more practice and help with the technology."

Other participants did not value online software with poorly developed aesthetics and design, (e. g. bad graphics, interface, and fluidity). In particular, the instructors noted that students were extremely critical of the interface.

[Quote from Participant 2, Female, First Year Student Top Quartile]

"The opening was incredibly slow. The graphics are laughable - the cheapest app game has better rendered people the frightening-looking person at the beginning. This may seem like a petty snipe, but students won't have any respect for an online exercise that looks that ridiculous."

According the instructors the step-by-step process of the software programs lessens student interest because the lack of realistic fluidity and openness of a real laboratory experience. In addition, the coding of the software was not refined and presented with faulty visual prompts and text creating discordant experiences.

\section{[Quote from Professor of Life Science 1]}

"The students here at XXX university I have do not like doing things on-line. I offer on-line homework, and they HATE it. They are not technologically savoy"

Theme 2: Life like details in the VR simulations. Reducing the fluidity of the experience via poor interface and missing things found in a "typical" lab (Realism) detracted from the learning experience. Instructors and students reported limitations associated with the simulation equipment, (i.e. the program crashing, lack of tactile feedback, and interactivity). This created difficulty for the immersive and fluid aspect of the experience, leading the students to see the VR laboratory as less than life-like and therefore not as good as the regular laboratories. The software also seemed to lack basic laboratory equipment found in tradition life science laboratories such as a microscope. However, there was an appreciation for safety procedures incorporated into the software.

[Quote from Participant 4, Female, First Year Student; Bottom Quartile]

"The lab was missing what I thought was basic lab equipment for biology, like a microscope and balance. Though I did have to practice with the safety equipment and that was something I have not done."

Other participants reported students did not value online software with poorly developed aesthetics and design, (e. g. bad graphics, interface and fluidity). It was noted that participants were extremely critical of the interface and stop working when the program did not load quickly enough.

[Quote from Participant 5, Male, First Year Student, Top Quartile]

"The beginning screen slow and even froze. The graphics were very low quality. This made me not want to use virtual reality, so I stopped."

Participants suggested that the step-by-step instruction and processes with in the software program lessens student interest because the lack of realistic fluidity, immersion, and authenticity. It greatly diminished the feel of a real laboratory experience. In addition, the coding of the software was not refined and presented faulty visual prompts and text creating discordant experiences. Importantly, the students felt the experience was filled with extraneous tasks (Participants 6 and 8). In addition, students (Participants 7 and 8, and 9) complained of a disconnect between the level of the laboratory exercise and the questions about the content given after the experience.

[Quote from Participant 6, Male, First Year Student, Top Quartile]

"There are better lab simulators out there. Clinical relevance is not appealing to everyone and the 
illustrations are crude. Students would lose interest quickly."

[Quote from Participant 7, Female, First Year Student, Top Quartile]

"That is nothing like the real world, where you constantly have to deal with them [safety goggles] fogging up and digging into your face. This isn't the same, and would only enforce poor behavior in the lab if a student ever found themselves there. Never mind you are not following a procedure but step by step doing things as they appear on the screen."

[Quote from Participant 8, Male, First Year Student, Bottom Quartile]

"Moreover, the absence of tactile skill development is a problem, and this might then be simply reduced to a theoretical exercise instead of some attempt to create this virtual experience. So much time was spent doing silly chores i.e. putting on a lab coat and maneuvering around the lab that the students will actually forget what the purpose of the lab is."

[Quote from Participant 9, Female, First Year Student, Bottom Quartile]

"I found the software to be rather rigid. It gives the appears of a sandbox type environment, yet it constrains students to stick to a specific script. The simulation here was too basic compared to the questions given afterward."

Theme 3: Real-world laboratory. Students and instructors noted that locating content within the software that was at the appropriate instructional level and that also supplemented the course curriculums was a challenge. While a positive attribute of the VR lab is that there was a reduced need for physical space, this did not seem to make up for the other areas of concern noted by the instructors and students. Thus, the benefit of VR from a cost perspective did not out weight the lack of realism and content. Specifically, the instructors felt that tactile skill development was deeply hindered by the lack of virtual reality interactivity.

[Quote from Participant 3, Male, First Year Student, Top Quartile]

"I have been unable to find level-appropriate genetics simulations for my majors genetics course, and I believe these labs do an adequate job of filling that niche"

[Quote from Participant 6, Male, First Year Student, Top Quartile]

"I can't see using this even as a supplement to an inperson lab or in a class that does not have a lab section, because there is so much hunt-and-peck and such a segmented nature to the information that I think it would frustrate students more than the benefit they would get out of it."

[Quote from Professor of Life Science 2]

"Click to run the thing didn't add a single lab-like experience to the information. As a supplement to traditional wet lab experience. I would make these modules a prelab practice and believe that it will help students a lot. Many of our students are going into hands on professions and they need to work in the environment in order to gain that hands-on experience."

Theme 4. Skill development. The instructors expressed concerns about how well the skills in the VR experiences would be able to develop and transfer to appropriate hands-on wet laboratory skills. The instructors were concerned that the VR did not offer sufficient experiences to promote this important aspect of learning.

\section{[Quote from Professor of Life Science 3]}

"Students need a wet chemistry hands on lab experience and this virtual experience does not make up for that in any way."

Theme 5: The link between content and the assessment. The assessment aspects of the software's module offered multiple-choice questions that participants (students 2 and 3), found to be unrelated to the presented content. More importantly because of the random nature of the question presentations, the participants felt that the content was disjoined and not logically connected creating frustration. Additionally, there was concern about the incongruence between the sophistication of the questions and the rudimentary nature of the simulation (Professor 2 and 4). At times, it was reported that the correct answer was missing from the options initially, only to appear after going back to the questions section and answering again.

[Quote from Participant 2, Female, First Year Student Top Quartile]

"I was given only half of the answers to the multiplechoice question, forcing me to choose an incorrect answer and have that impact my score. A student would find that infuriating. The scrolling requirement on the questions also meant that I couldn't see the answer choices and the question at the same time, which was an annoyance."

[Quote from Participant 8, Male, First Year Student, Bottom Quartile]

"I also feel students can easily just 'click' on the answers until they get the correct answer, without really getting or understanding the concepts. "The 
correct answers to the quizzes are not always there, then appear after hitting "back" several times. This was a waste of time."

\section{[Quote from Professor of Life Science 2]}

"To supplement a traditional lab course in Biotechniques, where we actually do an enzyme kinetics lab on Lactate dehydrogenase now. AND This would be a valuable learning tool for supplementing traditional hands-on lab experiences."

[Quote from Professor of Life Science 4]

"Virtual labs will not prepare students for laboratory work in graduate school, medical school, or in industry. In addition, American Chemical Society accredited programs will not permit the replacement of wet labs with virtual ones to meet the requirements for the degree."

Theme 6: Technical aspects of the software use. The software installation was problematic for some students'. Problems with the software made students reluctant to engage in multiple attempts to download and install it. Students reported the software refreshed on its own during the program forcing students to start from the beginning of modules. Instructors also expressed a concern about the cost of the software and associated hardware in comparison to the books they already use.

\section{[Quote from Professor of Life Science 1]}

"When you are trying to teach a student idea through a case study or simulation, they have to be able to both see the value in doing it and not have huge technological hurdles in doing so. What annoys them most is feeling that they are going through something that takes a lot of time for no reason. I felt like the entire thing as far as I saw was going through it for no reason. I would not use this in a class."

\section{[Quote from Professor of Life Science 3]}

"Many other computer software programs are costprohibitive, as I don't want students to purchase an expensive access code as well as a textbook - especially for labs that cover only a cursory review of in-depth concepts.

[Quote from Participant 7, Female, First Year Student, Top Quartile]

"I spent about 15 minutes trying to get through the first exercise and gave up because I kept getting error messages on what I was doing without being told how to navigate through it. I tried looking at several simulations. I tried different browsers and none of the simulations would load. Navigation through the program is unwieldy and time-wasting. I don't see any application of this format of instruction for microscope usage."

[Quote from Participant 3, Male, First Year Student, Top Quartile]

"Had trouble clicking the glove box (had to click out of it and then back in); could not get incision to work during dissection. Had some technical difficulties but glad we are exploring it."

In summary, there is consensus that the VR laboratory is not a replacement for real life laboratories for a variety of reasons. These reasons seem to align with the need for EVR simulations to provide immersion, fluidity, and authenticity in relation to the content and questions found in the environment. In addition, performance concerns about the program also inhibit wide spread adoption of the VR platform for use by students either as a supplement or as a replacement for existing laboratories.

\section{DISCUSSION}

The general assessment of the VR laboratory by the classroom instructors and students seems to be that the VR fails to meet the student's needs associated with studies in the life sciences. This is particularly true when the learning activities, tasks, and assessments are designed without specific pedagogical approaches embedded into the EVR as suggested by Annetta (2008) and Lamb (2015). Importantly not only did the student themselves request good pedagogical approaches be embedded in the software they also identified the user interface as a key concern. As instructional designers or educators develop and deploy specific features of virtual reality into their 3D VR laboratory courses, there is a need to consider the student end user experience (i.e. frustration, student training, instructor training, and infrastructure to support the VR laboratories).

One of the most promising aspects of the use of VR in the classroom is the ability to develop interactive, highly controlled, ultra-realistic, learning environments and experiences which were called for specifically by the participants in this study. Appropriate pedagogical approaches involving construction of knowledge in a virtual environment require that interactions with the EVR environment have a minimum level of fluidity, immersion, and authenticity allowing realistic interactions. Without this critical level of fluidity of interaction with the environment the learning process is too difficult to sustain and students will not persist.

Studies have found that, interactions in a VR environment can be a reasonable and valuable substitute for real life experiences (Lamb et al., 2019). However, as in the case of this study, affective aspects of the interaction, such as frustration, will impede the learning 
process and develop rather quickly when working with difficult user interfaces.

During the VR interactions learners attempted to undertake actions allowing them to put new understanding and new skills into practice, however these activities were frustrated. In considering future designs interactions must occur in a life-like and measured way. Lack of realism in the environment will result in less engagement and application of the learned content. While VR environments may allow learners to acquire knowledge with less difficulty than that of traditional learning process, poor organization of the environment will have the opposite outcome.

Collaboration in the VR learning environment is just as important as collaboration in the real world. In the case of this VR environment, the interaction was solely learner with content and did not afford the user person to person interactions. By completely removing the instructors and other students from the interactions, this VR environment misses critical times for social construction of new knowledge through interactions which are vital to student growth and success. Student interactions with other students allow the exchange of information and ideas as the students construct understanding and apply content. The transfer of skills from the VR environment to real world environments is of critical concern to educators. In order to accomplish this transition from one to the other, VR environments require immersion and realism along with the ability to construct knowledge through interaction. Immersion and realism will allow VR tools to train for similar tasks and reasoning in the real world as found in other studies (Lamb, 2016; Lamb, Annetta, Firestone, \& Etopio, 2018). As a result, VR environments provide rich teaching opportunities and help to improve learners' ability to analyze problems and explore new concepts associated with the environment. The multisensory aspect of the VR technology promotes greater learner engagement by prompting attention and stimulating curiosity. In the case of this VR environment, the multisensory aspect of the environment impeded learning due to the lack of high quality visuals, poor performance of the application, poor assessment, and poor feedback from the environment. That is, features of interaction and immersion will only take a student so far into the environment, if the environment is not fluid and highly responsive. Fluidity and responsiveness are the main characteristics, which maintain student engagement into the environment.

While the ability to engage in high repetition with minimal resource cost is an attractive trait of VR, rote repetition and lack of instruction will frustrate and confound student learning. In addition, the ability of the VR content to communicate the desired outcomes is incredibly important particularly is the student becomes lost or unsure of what to do next. As one seeks to build VR environments it is also important to consider the mode of assessment and to assure, the assessments meets the appropriate level and needs of the learner. One of the challenges in the design of EVR environments is how to integrate EVR features with authentic assessment. With EVR it is possible to not only assess in a traditional written manner, but to assess though actual skill and application approaches. Learning outcomes may be improved if guidance and scaffolding tools are provided and successfully integrated into EVR in a fluid and dynamic manner. For example, digital mentors with basic interactivity and instructions can promote and redirect learners in a meaningful way to ensure continuous movement toward specific learning outcomes and objectives.

\section{Conclusion}

While this EVR environment was missing several instructionally important characteristics such as feedback, development of literacy, and successive skill development, results from this study provide insight for the exploration of needed characteristics for future iterations of laboratory EVR environments. As more students and instructors focus on VR technology and VR applications for education, content will become easier to use and incorporate a priori pedagogical approaches as called for in other research (Annetta, 2010). To promote the use of VR for learning, educators need to understand the challenges students face when using VR technology for instruction for the first time and understand the limitation of the environment rather than counting on the novelty to maintain and promote outcomes. It is imperative that an instructor making use of VR, keep in mind, that VR is another tool to promote learning and not meant to replace the instructor.

\section{Limitations and Future Research}

The primary limitation of this examination of VR laboratory environments is the lack of exploration of specific attitudes around the use of technology in the classroom as they relate to science. In addition, the authors did not assess the relative levels of training for instructors and students making use of the VR environments or the prior science content knowledge. Further to this point the use of phone-based VR systems as compared to more robust headsets such as a Vive or Oculus $S$ which connect computers may have limited the functionality of the systems due to processor and graphical limitations. The small non-random sample of participants creates difficulty in the generalization of the findings to larger population of university students. Future studies will need to more directly assess the amount and types of support needed to successfully employ VR in the classroom. 


\section{Recommendations for Design of VR Environments for Classroom Use}

Due to the immersive nature of VR as the primary means to promote learning, anything that breaks the immersion is detrimental to the process of learning. As such, the fluidity of the user interface is of key importance. The user interface must consist of easy-touse, intuitive, life like gestures. As with many technologies, VR environments are often designed from a functional perspective rather than ease of use for the end user and even less so with a focus on learning. While this may change as the technology matures this is not currently the case. The most common difficulties for VR navigation is in using a $3 \mathrm{D}$ interface. As noted in this study, learners may easily get lost or be unable to navigate their VR environments. Poor usability severely limits the effectiveness of the instruction. Learner skill levels and familiarity in using VR must be accounted for in the development of EVR environments. Both the learner's knowledge of content and the learner's skill with VR user interface are important.

Although there are an increasing number of applications that support teaching and learning in a VR environment, perhaps the largest determining factor for user acceptance is how easily accessible a VR interface is for non-technical instructors. Thus, institutional support, training, and resources is necessary for educators making use of VR environments for science learning. VR environments and software must be examined in terms of cost effectiveness particularly in comparison to the wet laboratory experience. To that end, VR developers need to consider the cost of the VR system to the end user and how quickly the system will age and be out-of-date with current technologies (i.e. the shelf life of the technology). VR technology is expensive when using hardware such as head-mounted displays and cell phones to process the imaging. Many schools and individual students cannot afford the cost.

When educators design an environment in order to deliver complex concepts, it is necessary to ensure the presence of the three features of interaction, immersion and authenticity. Weighting one over the other necessitates shifts in pedagogical design and consideration in much the same way one designs SEGs (Annetta, 2010; Lamb, 2013). It is important for educators and instructional designers to understand how emphasis on one of the three features (interaction, immersion and authenticity) determines learning outcomes in a VR environment in the science classroom (Kirschner \& van Merrenboer, 2013).

\section{REFERENCES}

Annetta, L. A. (2010). The "I's" have it: A framework for serious educational game design. Review of General Psychology, 14(2), 105. https://doi.org/10.1037/ a0018985
Baldominos, A., Saez, Y., \& del Pozo, C. G. (2015). An approach to physical rehabilitation using state-ofthe-art virtual reality and motion tracking technologies. Procedia Computer Science, 64, 10-16. https://doi.org/10.1016/j.procs.2015.08.457

Bower, M., Lee, M. J., \& Dalgarno, B. (2017). Collaborative learning across physical and virtual worlds: Factors supporting and constraining learners in a blended reality environment. British Journal of Educational Technology, 48(2), 407-430. https:/ / doi.org/10.1111/bjet.12435

Calleja, G. (2014). Immersion in virtual worlds (pp. 222236). New York: Oxford University Press. https:/ / doi.org/10.1093/oxfordhb/978019982616 2.013.012

Calogiuri, G., Litleskare, S., Fagerheim, K. A., Rydgren, T. L., Brambilla, E., \& Thurston, M. (2017). Experiencing Nature through Immersive Virtual Environments: Environmental Perceptions, Physical Engagement, and Affective Responses during a Simulated Nature Walk. Frontiers in Psychology, 8, 2321. https://doi.org/10.3389/ fpsyg.2017.02321

Choi, A., Hand, B., \& Greenbowe, T. (2013). Students' written arguments in general chemistry laboratory investigations. Research in Science Education, 43(5), 1763-1783. https://doi.org/10.1007/s11165-0129330-1

Clark, R. C., \& Mayer, R. E. (2016). E-learning and the science of instruction: Proven guidelines for consumers and designers of multimedia learning. John Wiley \& Sons. https:/ / doi.org/10.1002/9781119239086

Cordie, L., Lin, X., \& Whitton, N. (2017). Utilizing Digital Educational Games to Enhance Adult Learning. Handbook of Research on Program Development and Assessment Methodologies in K-20 Education, 171. https: / / doi.org/10.4018/978-1-5225-3132-6.ch009

Crawford, B. A., Capps, D. K., van Driel, J., Lederman, N., Lederman, J., Luft, J. A., \& Smith, K. (2014). Learning to teach science as inquiry: Developing an evidence-based framework for effective teacher professional development. In Topics and Trends in Current Science Education (pp. 193-211). Springer Netherlands. https:/ / doi.org/10.1007/978-94-0077281-6_12

Dalgarno, B., \& Lee, M. J. (2010). What are the learning affordances of 3-D virtual environments?. British Journal of Educational Technology, 41(1), 10-32. https:/ / doi.org/10.1111/j.1467-8535.2009.01038.x

Davis, K., \& Singh, S. (2015). Digital badges in afterschool learning: Documenting the perspectives and experiences of students and educators. Computers $\mathcal{E}$ Education, 88, 72-83. https://doi.org/ 10.1016/j.compedu.2015.04.011 
Decristan, J., Klieme, E., Kunter, M., Hochweber, J., Büttner, G., Fauth, B., ... Hardy, I. (2015). Embedded formative assessment and classroom process quality: How do they interact in promoting science understanding?. American Educational Research Journal, 52(6), 1133-1159. https:/ / doi.org/10.3102/ 0002831215596412

Dunleavy, M., \& Dede, C. (2014). Augmented reality teaching and learning. In Handbook of research on educational communications and technology (pp. 735745). Springer New York. https:/ / doi.org/10.1007 /978-1-4614-3185-5_59

Freeman, S., Eddy, S. L., McDonough, M., Smith, M. K., Okoroafor, N., Jordt, H., \& Wenderoth, M. P. (2014). Active learning increases student performance in science, engineering, and mathematics. Proceedings of the National Academy of Sciences, 111(23), 84108415. https:/ / doi.org/10.1073/pnas.1319030111

Grassi, P. R., Zaretskaya, N., Bartels, A., Goerke, S., Milde, K. S., Bukowiecki, R., \& Wanker, E. E. (2015). Eye Tracking and Visualization: Foundations, Techniques, and Applications: ETVIS 2015. NeuroImage, 144, 1-17.

Gray, L., Thomas, N., \& Lewis, L. (2010). Teachers' use of educational technology in US public schools: 2009.

Hamari, J., Shernoff, D. J., Rowe, E., Coller, B., AsbellClarke, J., \& Edwards, T. (2016). Challenging games help students learn: An empirical study on engagement, flow and immersion in game-based learning. Computers in Human Behavior, 54, 170-179. https:// doi.org/10.1016/j.chb.2015.07.045

Hancock, P. A., Mercado, J. E., Merlo, J., \& Van Erp, J. B. (2013). Improving target detection in visual search through the augmenting multi-sensory cues. Ergonomics, 56(5), 729-738. https:/ / doi.org/10.1080 /00140139.2013.771219

Jasper, J. M. (2011). Emotions and social movements: Twenty years of theory and research. Annual Review of Sociology, 37, 285-303. https://doi.org/10.1146/ annurev-soc-081309-150015

Katz, J. E., \& Halpern, D. (2015). Can virtual museums motivate students? toward a constructivist learning approach. Journal of Science Education and Technology, 24(6), 776-788. https:// doi.org/10.1007 / s10956-015-9563-7

Kirschner, P. A., \& van Merriënboer, J. J. (2013). Do learners really know best? Urban legends in education. Educational psychologist, 48(3), 169-183. https: / / doi.org/10.1080/00461520.2013.804395

Klatzky, R. L., Giudice, N. A., Bennett, C. R., \& Loomis, J. M. (2014). Touch-screen technology for the dynamic display of 2D spatial information without vision: Promise and progress. Multisensory research,
27(5-6), 359-378. https://doi.org/10.1163/22134 808-00002447

Kutlu, M. O. (2012). Developing a scale on the usage of learner control strategy. Educational Research and Reviews, 7(10), 244. https://doi.org/10.5897/ ERR11.302

Lamb, R. (2014). Examination of allostasis and online laboratory simulations in a middle school science classroom. Computers in Human Behavior, 39, 224234. https:/ / doi.org/10.1016/j.chb.2014.07.017

Lamb, R. L. (2013). The application of cognitive diagnostic approaches via neural network analysis of serious educational games (Doctoral dissertation, George Mason University). Retrieved from https:/ / hdl.handle.net/1920/8342

Lamb, R. L. (2016). Examination of the Effects of Dimensionality on Cognitive Processing in Science: A Computational Modeling Experiment Comparing Online Laboratory Simulations and Serious Educational Games. Journal of Science Education and Technology, 25(1), 1-15. https:/ / doi.org/10.1007/s10956-015-9587-z

Lamb, R. L., \& Annetta, L. (2013). The use of online modules and the effect on student outcomes in a high school chemistry class. Journal of Science Education and Technology, 22(5), 603-613. https:/ / doi.org/10.1007/s10956-012-9417-5

Lamb, R. L., Annetta, L., Firestone, J., \& Etopio, E. (2018). A meta-analysis with examination of moderators of student cognition, affect, and learning outcomes while using serious educational games, serious games, and simulations. Computers in Human Behavior, 80, 158-167. https://doi.org/10.1016/ j.chb.2017.10.040

Lamb, R., \& Annetta, L. (2012). Influences of gender on computer simulation outcomes. Meridian, 13(1). Retrieved from http:/ / www.ncsu.edu/meridian/ review/winter2010/lamb/

Lamb, R., Annetta, L., \& Vallett, D. (2015). The interface of creativity, fluency, lateral thinking and technology while designing Serious Educational Games in a science classroom. Electron J Res Educ Psychol, 13(2), 219-242. https://doi.org/10.14204/ ejrep.36.14110

Lamb, R., Etopio, E., \& Lambi, R.E. (2019) Virtual reality play therapy. International Journal of Play Therapy

Lawson, G., Salanitri, D., \& Waterfield, B. (2016). Future directions for the development of virtual reality within an automotive manufacturer. Applied ergonomics, 53, 323-330. https://doi.org/10.1016/ j.apergo.2015.06.024

Lin, T. J., \& Yu-Ju, L. (2015). Language learning in virtual reality environments: Past, present, and future. Journal of Educational Technology \& Society, 18(4), 486. 
Lui, M., \& Slotta, J. D. (2014). Immersive simulations for smart classrooms: exploring evolutionary concepts in secondary science. Technology, Pedagogy and Education, 23(1), 57-80. https://doi.org/10.1080/ 1475939X.2013.838452

Makani, J., Durier-Copp, M., Kiceniuk, D., \& Blandford, A. (2016). Strengthening Deeper Learning Through Virtual Teams in E-learning: A Synthesis of Determinants and Best Practices. International Journal of E-Learning $\mathcal{E}$ Distance Education, 31(2).

Merchant, Z., Goetz, E. T., Cifuentes, L., KeeneyKennicutt, W., \& Davis, T. J. (2014). Effectiveness of virtual reality-based instruction on students' learning outcomes in K-12 and higher education: A meta-analysis. Computers $\mathcal{E}$ Education, 70, 29-40. https://doi.org/10.1016/j.compedu.2013.07.033

Nelson, D., \& Annetta, L. A. (2016). Creating Disruptive Innovators: Serious Educational Game Design on the Technology and Engineering Spectrum. In Connecting Science and Engineering Education Practices in Meaningful Ways (pp. 3-17). Springer International Publishing. https:/ / doi.org/10.1007/ 978-3-319-16399-4_1

Norton-Meier, L., Hand, B., Hockenberry, L., \& Wise, K. (2008). Questions, claims, and evidence: The important place of argument in children's science writing. Heinemann.

Pinson, M. H., Barkowsky, M., \& Le Callet, P. (2013). Selecting scenes for 2D and 3D subjective video quality tests. EURASIP Journal on Image and Video Processing, 2013(1), 50. https://doi.org/10.1186/ 1687-5281-2013-50

Potkonjak, V., Gardner, M., Callaghan, V., Mattila, P., Guetl, C., Petrović, V. M., \& Jovanović, K. (2016). Virtual laboratories for education in science, technology, and engineering: A review. Computers $\mathcal{E}$ Education, 95, 309-327. https:/ / doi.org/10.1016/ j.compedu.2016.02.002

Procci, K. (2015). The subjective gameplay experience: An examination of the revised game engagement model.

Psotka, J. (2013). Educational Games and Virtual Reality as Disruptive Technologies. Educational Technology $\mathcal{E}$ Society, 16(2), 69-80.

Rao, S. S. (2013). The Finite Element Method in Engineering: Pergamon International Library of Science, Technology, Engineering and Social Studies. Elsevier.

Richards, D., \& Taylor, M. (2015). A Comparison of learning gains when using a 2D simulation tool versus a 3D virtual world: An experiment to find the right representation involving the Marginal Value Theorem. Computers \& Education, 86, 157-171. https:/ / doi.org/10.1016/j.compedu.2015.03.009

Riva, G., Baños, R. M., Botella, C., Mantovani, F., \& Gaggioli, A. (2016). Transforming experience: the potential of augmented reality and virtual reality for enhancing personal and clinical change. Frontiers in Psychiatry, 7. https://doi.org/10.3389/ fpsyt.2016.00164

Rosenblatt, V., Worthley, R., \& MacNab, B. (2013). From contact to development in experiential cultural intelligence education: The mediating influence of expectancy disconfirmation. Academy of Management Learning E Education, 12(3), 356-379. https:/ / doi.org/10.5465/amle.2012.0199

Santos, M. E. C., Chen, A., Taketomi, T., Yamamoto, G., Miyazaki, J., \& Kato, H. (2014). Augmented reality learning experiences: Survey of prototype design and evaluation. IEEE Transactions on learning technologies, $\quad 7(1)$ 38-56. https:/ / doi.org/10.1109/TLT.2013.37

Savin-Baden, M., Poulton, T., Beaumont, C., \& Conradi, E. (2016). What is real? Using problem-based learning in virtual worlds. In Educational technologies in medical and health sciences education (pp. 79-97). Springer International Publishing. https:/ / doi.org/10.1007/978-3-319-08275-2_5

Schofield, D. (2014). A virtual education: guidelines for using games technology. Journal of Information Technology Education, 13, 25-43. https://doi.org/ $10.28945 / 1964$

Sharma, S., Agada, R., \& Ruffin, J. (2013, April). Virtual reality classroom as an constructivist approach. In Southeastcon, 2013 Proceedings of IEEE (pp. 1-5). https:/ / doi.org/10.1109/SECON.2013.6567441

Shute, V., Rahimi, S., \& Emihovich, B. (2017). Assessment for Learning in Immersive Environments. In Virtual, Augmented, and Mixed Realities in Education (pp. 71-87). Springer, Singapore. https://doi.org/ 10.1007/978-981-10-5490-7_5

Tan, D., \& Nijholt, A. (2010). Brain-computer interfaces and human-computer interaction. In BrainComputer Interfaces (pp. 3-19). Springer London. https:/ / doi.org/10.1007/978-1-84996-272-8

Vaughan, N., Gabrys, B., \& Dubey, V. N. (2016). An overview of self-adaptive technologies within virtual reality training. Computer Science Review, 22, 65-87. https://doi.org/10.1016/j.cosrev.2016.09. 001

Vygotsky, L. S. (2016). Play and Its Role in the Mental Development of the Child. International Research in Early Childhood Education, 7(2), 3-25.

Waight, N., Liu, X., Gregorius, R. M., Smith, E., \& Park, M. (2014). Teacher conceptions and approaches associated with an immersive instructional implementation of computer-based models and assessment in a secondary chemistry classroom. International Journal of Science Education, 36(3), 467505. https://doi.org/10.1080/09500693.2013. 787506 
Wood, L. C., \& Reiners, T. (2015). Storytelling to immersive learners in an authentic virtual training environment. In Gamification in Education and Business (pp. 315-329). Springer, Cham. https://doi.org/10.1007/978-3-319-10208-5_16
Yoon, S. Y., Choi, Y. J., \& Oh, H. (2015). User attributes in processing 3D VR-enabled showroom: Gender, visual cognitive styles, and the sense of presence. International Journal of Human-Computer Studies, 82, 1-10. https:/ / doi.org/10.1016/j.ijhcs.2015.04.002

\section{http://www.ejmste.com}

